\title{
Varenicline for smoking cessation: efficacy, safety, and treatment recommendations
}

\author{
This article was published in the following Dove Press journal: \\ Patient Preference and Adherence \\ 10 September 2010 \\ Number of times this article has been viewed
}

\author{
Jon O Ebbert \\ Kirk D Wyatt \\ J Taylor Hays \\ Eric W Klee \\ Richard D Hurt \\ Mayo Clinic College of Medicine, \\ Rochester, MN, USA
}

Correspondence: Jon O Ebbert Mayo Clinic College of Medicine, Mayo Clinic, 200 First Street Southwest, Rochester, MN 55905, USA

Tel +I 507266 I 944

Fax +I 5072667900

Email ebbert.jon@mayo.edu

\begin{abstract}
Smoking is the leading preventable cause of morbidity and mortality in the US, and decreasing smoking prevalence is a public health priority. Patients achieve the greatest success when quit attempts involve behavioral therapy combined with pharmacotherapy. Varenicline is the most recent addition to the pharmacotherapeutic armamentarium for the treatment of tobacco dependence. Varenicline is efficacious and cost-effective. Smoking relapse and adverse treatment-related side effects may decrease medication adherence and patient satisfaction with varenicline. In the clinical setting, varenicline treatment can be optimized by reducing doses in patients who experience intolerable side effects, increasing the dose in partial responders, and providing long-term maintenance therapy for relapse prevention.
\end{abstract}

Keywords: varenicline, tobacco dependence, smoking cessation, nicotine addiction

\section{Introduction}

Despite the profound adverse health consequences of cigarette smoking, 46 million (20.6\%) US adults continue to smoke every day or some days. ${ }^{1}$ On average, cigarette smokers will lose between 13 and 15 years of life as a direct consequence of smoking. ${ }^{2}$ Over one-half of all lifetime smokers will die from smoking-related illness, ${ }^{3}$ and one out of every five deaths annually in the US is attributable to smoking. ${ }^{4,5}$ Direct health care costs related to illnesses caused by tobacco have been estimated at $\$ 96$ billion per year. ${ }^{6}$

Smoking-related deaths are preventable, and stopping smoking has an immediate and dramatic impact on health and well being. Smoking abstinence reduces the risk of myocardial infarction and cardiovascular death. After one year of smoking abstinence, the excess risk (versus never smokers) of coronary heart disease mortality declines by one half. ${ }^{7}$ Risk of cardiovascular death among coronary heart disease patients who quit smoking is about half that of coronary heart disease patients who continue smoking ${ }^{7,8}$ Fifteen years after quitting, the risk of coronary heart disease in former smokers is comparable with that of never smokers. ${ }^{7}$ After $5-15$ years of smoking abstinence, the risk of stroke in a former smoker falls to that of a never smoker. $^{7}$

Among patients with chronic obstructive pulmonary disease, stopping smoking decreases the rate of decline in lung function, chronic obstructive pulmonary diseaserelated mortality, and all-cause mortality. ${ }^{9}$ Ten years after quitting, the risk of lung cancer in former smokers is $50 \%-70 \%$ less than that of continuing smokers. ${ }^{7}$ 


\section{Comprehensive tobacco dependence treatment}

In 2000 , an estimated $70 \%$ of US smokers had a desire to quit, and $40 \%$ made a quit attempt in the previous year. ${ }^{10}$ Smokers who seek and receive treatment in the form of behavioral and/ or pharmacologic therapy are more successful at quitting than those who do not seek help, yet only $20 \%$ of smokers who make a quit attempt will actually seek help. ${ }^{11}$ Most smokers who make unaided quit attempts relapse within eight days of quitting, and $\leq 5 \%$ of unaided quitters will achieve sixmonth prolonged smoking abstinence. ${ }^{12}$ Clinicians should offer behavioral therapy and pharmacotherapy to all smokers who express a desire to quit. ${ }^{13}$

\section{Behavioral interventions}

Behavioral strategies (eg, intratreatment social support, practical counseling) are effective for increasing smoking abstinence rates. ${ }^{13}$ While even brief ( $<3$ minutes per session) counseling is effective for promoting smoking abstinence, more intensive behavioral interventions are proportionally more effective. A meta-analysis observed the impact of behavioral counseling intensity on smoking abstinence to be dose-dependent, with high-intensity (ie, $>10$ minutes per session) counseling yielding higher smoking abstinence rates than low-intensity (ie, $<3$ minutes per session) counseling (odds ratios [OR] 2.3, 95\% confidence intervals [CI]: 2.0-2.7 and OR 1.3, 95\% CI: 1.01-1.6, for high-intensity and low-intensity counseling compared with no intervention, respectively).$^{13}$ Behavioral counseling represents an integral component of comprehensive tobacco dependence treatment and is increasingly provided by nonphysician health care professionals trained as tobacco treatment specialists.

\section{Pharmacotherapy}

Seven "first-line" pharmacotherapies for tobacco dependence are currently available in the US, ie, sustained-release bupropion, varenicline, and five forms of nicotine replacement therapy (ie, patch, gum, lozenge, inhaler, nasal spray). ${ }^{14}$ Two "second-line" treatments, clonidine and nortriptyline, are available, but have not received an indication for treating smokers by the US Food and Drug Administration (FDA).${ }^{13}$ The present review will focus on treatment with varenicline.

\section{Varenicline}

\section{Mechanism of action}

The mechanism by which varenicline assists smokers in achieving smoking abstinence must be understood within the context of the role that nicotine plays in fostering tobacco dependence. Nicotine is the chemical in cigarette smoke leading to addiction. ${ }^{15}$ Upon inhaling cigarette smoke, nicotine is quickly absorbed into the bloodstream and readily penetrates the blood-brain barrier. Nicotine subsequently acts on neuronal nicotinic acetylcholine receptors within the ventral tegmental area of the brain, causing dopamine release in the nucleus accumbens which reinforces nicotine-seeking behavior. ${ }^{16}$ Reward through the dopaminergic system is a common thread among many drugs of addiction. ${ }^{17}$

Nicotine is a promiscuous ligand, binding to many nicotinic acetylcholine receptor subtypes found in the central nervous system and peripheral nervous system. ${ }^{16,18}$ Human neural nicotinic acetylcholine receptors are pentameric ion channels structurally composed of 11 subunits $\left(\alpha_{2}-\alpha_{7}, \alpha_{9}\right.$, $\left.\alpha_{10}, \beta_{2}-\beta_{4}\right)$. The predominant neuronal nicotinic acetylcholine receptor subtypes in the central nervous system are the $\alpha_{4} \beta_{2}$ and $\alpha_{7}$ varieties. ${ }^{19}$ Of these, the former is most prevalent in the central nervous system, accounting for approximately $90 \%$ of central nervous system neuronal nicotinic acetylcholine receptors. ${ }^{19}$ This high prevalence and the high nicotine affinity of $\alpha_{4} \beta_{2}$ neuronal nicotinic acetylcholine receptors for nicotine suggest that the $\alpha_{4} \beta_{2}$ neuronal nicotinic acetylcholine receptor is a key biomolecular target for the perpetuation of and treatment of nicotine addiction. ${ }^{20}$

Cytisine, an $\alpha_{4} \beta_{2}$ neuronal nicotinic acetylcholine receptor partial agonist, has been used for over 50 years for smoking cessation in Eastern Europe. . $^{2122}$ During World War II, smokers used leaves from Cytisus laburnum, a cytisinecontaining plant, in place of tobacco. ${ }^{22}$ Although studies on cytisine appeared mildly promising, and a meta-analysis ${ }^{22}$ concluded that it may be an effective pharmacotherapeutic aid for smoking cessation, several of the studies included in the meta-analysis had methodologic limitations. Consequently, the drug's efficacy remained in doubt and appeared to be limited by inadequate absorption and/or central nervous system penetration. ${ }^{23-25}$ The cytisine molecule was used as the structural basis for the ligand-based drug design of varenicline which could pass freely into the central nervous system..$^{25}$

Varenicline possesses a receptor-dependent mode of action, acting as a low-efficacy partial agonist to the $\alpha_{4} \beta_{2}$, $\alpha_{3} \beta_{2} \alpha_{3} \beta_{4}$ and $\alpha_{6} / \alpha_{3} \beta_{2} \beta_{3}$ chimeric neuronal nicotinic acetylcholine receptor and a high-efficacy full agonist to the $\alpha_{7}$ neuronal nicotinic acetylcholine receptor. The functional potency of varenicline is $8-24$ times greater at the $\alpha_{4} \beta_{2}$ compared with the $\alpha_{7}$ and $\alpha_{3} \beta_{4}{ }^{26}$ The equilibrium binding affinity of $\alpha_{4} \beta_{2}$ compared with $\alpha_{7}$ and $\alpha_{3} \beta_{4}$ for varenicline has been reported to be two orders of magnitude more specific than the functional potency, ${ }^{25}$ perhaps reflecting 
affinity for the receptor in the desensitized state. ${ }^{26}$ As a pharmacologic agent for tobacco dependence, varenicline's partial agonism of the $\alpha_{4} \beta_{2}$ is thought to promote smoking abstinence through stimulation of dopaminergic neurons and consequent amelioration of tobacco cravings and nicotine withdrawal. ${ }^{25}$ Partial antagonism at the $\alpha_{4} \beta_{2}$ neuronal nicotinic acetylcholine receptor inhibits binding of nicotine, leading to diminished reward from smoking a cigarette. ${ }^{25}$ Pharmacologic studies in rats have demonstrated that the relative agonist efficacy of varenicline is $40 \%-60 \%$ (relative to nicotine) and the relative nicotine antagonist efficacy is $40 \%-55 \% .^{25}$

Varenicline has been observed to dampen the desire to smoke. Compared with placebo, craving is significantly lower for participants who receive varenicline (versus placebo, $P<0.001) .{ }^{27,28}$ Consistent with the proposed partial antagonist mechanism for varenicline, smoking satisfaction, and psychologic reward are also significantly decreased in smokers taking varenicline (versus placebo, $P<0.001) .^{27,28}$

\section{Dosing}

Varenicline treatment is initiated one week prior to the patient's target quit date. Dosing begins at $0.5 \mathrm{mg}$ once daily and increases to $0.5 \mathrm{mg}$ twice daily on day 4 . On the target quit date (day 8), the dose is increased to $1 \mathrm{mg}$ twice daily and maintained for 12 weeks.

\section{Clinical evidence for efficacy of varenicline}

Two large, identically designed, multicenter, double-blind, Phase III, randomized, controlled clinical trials provided convincing evidence of the efficacy of varenicline for the treatment of tobacco dependence. ${ }^{27,28}$ One study ${ }^{27}$ observed $44 \%$ continuous smoking abstinence during the last four weeks of treatment (weeks 9-12) for subjects taking $1 \mathrm{mg}$ varenicline twice daily compared with $18 \%$ for placebotreated subjects (OR 3.85, 95\% CI: 2.70-5.50) and 30\% for sustained-release bupropion-treated (150 mg twice daily) subjects (OR 1.93, 95\% CI: 1.40-2.68). ${ }^{27}$ At 52 weeks after randomization, varenicline significantly increased prolonged abstinence rates compared with placebo $(21.9 \%$ versus $8.4 \%$, OR 3.09, 95\% CI: 1.95-4.91) and had marginal benefit compared with sustained-release bupropion $(21.9 \%$ versus 16.1\%, OR 1.46, 95\% CI: 0.99-2.17). Findings from the second Phase III trial ${ }^{28}$ were nearly identical, except that varenicline increased prolonged smoking abstinence rates significantly compared with sustained-release bupropion at 52 weeks (OR 1.77, 95\% CI: 1.19-2.63).
Varenicline also appears to be more efficacious than nicotine replacement therapy. In an open-label study, ${ }^{29}$ participants randomly received varenicline (1 $\mathrm{mg}$ twice daily) for 12 weeks or transdermal nicotine replacement therapy (21 mg/day, tapered to $7 \mathrm{mg} /$ day) for 10 weeks. Prolonged smoking abstinence for the last four weeks of treatment was higher for varenicline-treated participants than patients receiving the nicotine patch $(56 \%$ versus $43.2 \%$, OR 1.70 , 95\% CI: 1.26-2.28). At one year, a trend was observed toward increased efficacy with varenicline compared with the nicotine patch for prolonged smoking abstinence (26\% versus $20 \%$ prolonged abstinence, OR 1.40, 95\% CI: 0.99-1.99).

A recent meta-analysis ${ }^{30}$ compiled the data from six clinical trials including 2583 participants receiving either varenicline or placebo. The analysis yielded a risk ratio (RR) for continuous smoking abstinence over weeks 9-24 of 2.34 (95\% CI: 1.99-2.75) favoring varenicline $1.0 \mathrm{mg}$ twice daily. The meta-analysis also reported on three studies that compared varenicline with sustained-release bupropion. Varenicline was observed to be superior to bupropion (RR 1.52, 95\% CI: 1.22-1.88) for continuous abstinence at week 52 .

Longer durations of therapy with varenicline have been shown to be more effective than shorter durations. In a study evaluating longer duration of therapy, ${ }^{31}$ participants achieving smoking abstinence at the end of treatment after 12 weeks with open-label varenicline were randomized to either varenicline $1 \mathrm{mg}$ twice daily or placebo for an additional 12 weeks. At the end of the second treatment phase (week 24 of the study), 71\% of participants receiving active treatment remained abstinent from smoking compared with $50 \%$ of participants receiving placebo (OR 2.48, 95\% CI: 1.95-3.16). After 52 weeks of follow-up, subjects receiving varenicline had significantly higher smoking abstinence rates compared with those receiving placebo (44\% versus $37 \%$ continuous abstinence over weeks $13-52$, OR 1.34, 95\% CI: 1.06-1.69).

A secondary analysis of the data from this study suggests that, when used for relapse prevention, the additional 12 -week course of varenicline is more effective in smokers who initially have difficulty achieving smoking abstinence. ${ }^{32}$ When treatment effect of maintenance therapy was analyzed separately for early quitters (ie, those who quit at week 1) and late quitters (ie, those who quit after the first week of treatment), the additional 12 weeks of maintenance therapy was more helpful for relapse prevention in late quitters (OR 1.7, 95\% CI: $1.2-2.4$ ) than in early quitters (OR 1.1, 95\% CI: $0.8-1.5)$. 
The safety and efficacy of long-term treatment ( $>$ six months) with varenicline has been demonstrated. In a study on 377 adult smokers, participants were randomized to varenicline ( $1 \mathrm{mg}$ twice daily) or placebo for 52 weeks. The drug was well tolerated. Most adverse effects were experienced during the first four weeks of the treatment phase and adverse event incidence decreased over time. The seven-day point prevalence smoking abstinence rate at week 52 was $37 \%$ for varenicline-treated subjects compared with $8 \%$ for the placebo group. ${ }^{33}$

\section{Varenicline in combination pharmacotherapy}

None of the available first-line medications for treating tobacco dependence have labeled indications for use in combination with another. However, multiple trials of combination therapy have been published, and show improved smoking abstinence rates compared with monotherapy. ${ }^{34}$ Combination therapy with varenicline has only been studied in small clinical trials to date. An open-label pilot study ${ }^{35}$ in smokers investigated 12 weeks of therapy with varenicline (standard treatment regimen) coadministered with sustained-release bupropion (150 mg twice daily after a three-day dose escalation). The seven-day point prevalence smoking abstinence rate among 38 enrolled smokers was $71 \%$ (95\% CI: 54-85) at the end of treatment. At six months, combination therapy continued to appear more effective than monotherapy, although an appropriately powered, double-blind, randomized, controlled trial is necessary to confirm these findings.

Combination therapy with varenicline and nicotine replacement therapy has also been evaluated. Heavier smokers might benefit from this combination because varenicline might not fully saturate nicotinic receptors during dose escalation. Incompletely saturated receptors may lead to partial attenuation of nicotine cravings. If supplemental nicotine replacement therapy can lead to more complete receptor saturation, then urges to smoke could be more completely attenuated. This possible effect was evaluated in an eightday residential treatment program. ${ }^{36}$ The first study group $(n=135)$ completed the residential treatment program prior to the release of varenicline and received "usual care" consisting of nicotine patch therapy and/or sustained-release bupropion. Short-acting forms of nicotine replacement therapy were used ad libitum for treatment of acute nicotine withdrawal symptoms. The second group $(\mathrm{n}=104)$ completed the residential treatment program after FDA approval of varenicline and received combination therapy with varenicline and nicotine replacement therapy. Nicotine patch therapy was the predominant form of nicotine replacement therapy used, and it was often supplemented with short-acting forms of nicotine replacement therapy. Nearly three-quarters of patients used more than one form of nicotine replacement therapy. No significant differences were observed in 30-day point prevalence smoking abstinence rates between the two groups at six months. Importantly, no increase in reported side effects in patients receiving the combination treatment was observed. Major limitations to this study were the small sample size and uncontrolled study design.

\section{Medication adherence}

Direct associations exist between adherence to medication therapy and treatment outcomes. One-fifth of smokers who receive medication for the treatment of tobacco dependence fail to fill their prescriptions. ${ }^{37}$ When patients start medication, medication adherence becomes an issue. In a post hoc analysis ${ }^{38}$ of data from the first two Phase III clinical trials on varenicline for treating tobacco dependence, ${ }^{27,28}$ a positive correlation between adherence to treatment regimen (defined as taking $\geq 1$ dose of study medication for $\geq 80 \%$ of days of the treatment period) and smoking abstinence was observed for all three study arms (varenicline, sustained-release bupropion, and placebo). This suggests a "healthy adherer effect" with individuals adhering to a prescribed treatment having more favorable outcomes independent of treatment assignment. Factors found to be significant predictors of smoking abstinence included older age, fewer number of cigarettes smoked per day, and achievement of early smoking abstinence. Achievement of smoking abstinence in the first two weeks was the most significant predictor of adherence.

To maximize drug efficacy, patients need to adhere to dosing guidelines. With this in mind, prescribers should consider factors that influence patient adherence, such as medication cost, dosing frequency, and the adverse effect profile. They should also educate patients about the rationale for treatment and possible side effects, and reinforce the importance of treatment adherence. ${ }^{38}$

\section{Medication cost}

Medication cost appears to influence both patient utilization of smoking cessation interventions and abstinence. One study randomized 1204 smokers to receive either a self-help video and pamphlet only or to the self-help video and pamphlet in addition to full insurance coverage for overthe-counter nicotine replacement therapy combined with group behavioral therapy at no cost. Participants were not 
obligated to make a quit attempt during the study. Providing full coverage of behavioral therapy and pharmacotherapy with no participant cost-sharing increased the rate of quit attempts (adjusted OR 1.4, 95\% CI: 1.1-1.8) and nicotine replacement therapy use (adjusted OR 2.3, 95\% CI: 1.6-3.2). One-year smoking abstinence rates were also higher in the group that received free medication and behavioral therapy (18\% versus $13 \%$ self-reported seven-day point prevalence smoking abstinence; adjusted OR 1.6, 95\% CI: 1.1-2.4). ${ }^{39}$ Another study observed that higher rates of tobacco treatment service utilization occurred among insured patients with full coverage compared with those with partial coverage (ie, cost-sharing). ${ }^{40}$ Notably, the full coverage group demonstrated lower smoking abstinence rates. However, the higher utilization among the fully-insured offset the lower abstinence rates, such that the overall prevalence of smoking was greater with full coverage than with the costsharing plans. A study of 7513 pregnant Medicaid enrollees who were smokers prior to pregnancy demonstrated that Medicaid coverage for treating tobacco dependence was directly associated with greater smoking abstinence rates. Female smokers in states providing extensive coverage (ie, pharmacotherapy and behavioral counseling) had a $51 \%$ quit rate during pregnancy compared with a $39 \%$ quit rate for women in states that provided no Medicaid coverage for tobacco dependence treatment (adjusted OR 1.58, 95\% CI: 1.00-2.49). Women who lived in states that provided only partial Medicaid coverage (ie, pharmacotherapy or counseling only) had intermediate smoking abstinence rates (43\%, adjusted OR versus no coverage $1.18,95 \%$ CI: $1.03-1.34) .{ }^{41}$ These studies indicate that comprehensive insurance coverage for tobacco dependence treatment can have a positive effect on smoking abstinence outcomes.

No generic formulation of varenicline is available, so the drug must be purchased as Chantix ${ }^{\circledR}$ in the US or Champix ${ }^{\circledR}$ elsewhere. Chantix costs roughly US \$4-5 per day for normal dosing, although this may vary regionally. ${ }^{13}$ Although patients often only consider the immediate and direct cost of medication, cost-benefit analyses have demonstrated the longterm cost effectiveness of varenicline. A cost-utility analysis factoring in direct medical costs of treating smoking-related disease estimated that varenicline is the most cost-effective pharmacotherapy for treating tobacco dependence in terms of cost per quality-adjusted life year. When a US population is used in the model, varenicline treatment for smokers costs US \$1884 per quality-adjusted life year, compared with \$1902, \$1912, and \$1922 for bupropion, nicotine replacement therapy, and unaided attempts to quit, respectively. ${ }^{42}$
The finding of superior cost-effectiveness for varenicline versus other treatments for smokers has been replicated in other simulations using different populations. ${ }^{43-46}$ Doubling the treatment duration with varenicline was more costly but still cost-effective. Simulations estimated an incremental cost of $\$ 972$ per quality-adjusted life year for a 24-week treatment when compared with 12 weeks. ${ }^{47}$ However, cost effectiveness does not translate into the calculation of cost for the individual patient. Clinicians need to be sensitive to cost, and explore with their patient ways to mitigate the financial burden posed by filling prescriptions and by minimizing side effects.

\section{Adverse effects of varenicline}

The most commonly reported adverse events experienced by subjects on varenicline in clinical trials were nausea $(28.1 \%$ versus $8.4 \%$ placebo), headache $(15.5 \%$ versus $12.2 \%)$, insomnia (14.0\% versus $12.8 \%$ ), and abnormal dreams (10.3\% versus 5.5\%). ${ }^{27}$ A recent meta-analysis compiled the available data on adverse events in these clinical trials with varenicline. Compared with placebo, varenicline increases the risk for nausea (RR 3.25, 95\% CI: 2.73-3.86), insomnia (RR 1.45, 95\% CI: 1.21-1.75), and abnormal dreams (RR $2.79,95 \%$ CI: $2.09-3.72) .{ }^{30}$ In clinical trials, only $8.6 \%$ of study subjects who received varenicline (versus $9.0 \%$ placebo) discontinued treatment due to adverse effects. ${ }^{27}$

Since 2007, reports of neuropsychiatric adverse events experienced by patients taking varenicline have evoked significant concern about the drug's safety. In November 2007, the FDA disclosed post-marketing surveillance data indicating reports of suicidal ideation, mood and behavior disturbances, and depression emerging in patients shortly after commencing treatment with varenicline. ${ }^{48}$ In 2008, the FDA mandated a revision to the Chantix product insert to include a warning that severe neuropsychiatric symptoms have been experienced by patients taking the drug. Health care providers are advised to monitor patients who take varenicline closely and patients are urged to seek a medical professional if neuropsychiatric adverse events are experienced. ${ }^{49}$ In 2009 , the FDA required that varenicline and bupropion both carry on their packaging "boxed" warnings, the strongest warning given by the FDA, about a possible link between the drug and the onset of neuropsychiatric adverse effects..$^{50}$

The recent case reports on adverse events with varenicline are challenging to interpret because the reports are anecdotal and the described events have also been observed among patients attempting to stop smoking. The Diagnostic and Statistical Manual of Mental Disorders (DSM-IV-TR) 
associates nicotine withdrawal with a plethora of adverse neuropsychiatric symptoms, including dysphoric or depressed mood, insomnia, irritability, frustration, anger, and anxiety. ${ }^{51}$ In an attempt to conduct a more rigorous assessment of the safety profile of varenicline, a pooled analysis of psychiatric adverse events from 10 randomized, controlled trials treating a total of 3091 participants with varenicline was performed. The analysis reported no significant increase in overall psychiatric disorders due to varenicline other than sleep disorders and disturbances (RR 1.70, 95\% CI: 1.50-1.93). ${ }^{52}$

Forthcoming clinical trials required by the FDA ${ }^{53}$ should paint a clearer picture of the incidence of neuropsychiatric adverse effects experienced by individuals, including smokers diagnosed with psychiatric disorders, using various treatment strategies for tobacco dependence.

\section{Recommendations for efficacy and adherence with varenicline}

The US Surgeon General has concluded that "the health benefits of smoking cessation far exceed any risks from ... adverse psychological effects that may follow quitting". ${ }^{7}$ Presently available data have not proven that varenicline causes significant neuropsychiatric adverse events. However, until more is known about potential neuropsychiatric adverse effects, clinicians should closely monitor patients who are taking varenicline. In the absence of a proven causal link between varenicline and a serious risk of neuropsychiatric adverse effects, the immense health benefits of smoking cessation warrant its continued use as a pharmacologic aid for treating tobacco dependence. Clinical monitoring is needed to ensure patient progress and safety.

The efficacy of varenicline is dependent upon adherence to medication therapy. Clinicians should choose appropriate treatments tailored to patient preferences and adjust the dosing regimen as needed to maximize adherence and efficacy and minimize patient discomfort. Communication is fundamental and clinicians should work to establish an open dialog with patients to discuss the importance of medication adherence, as well as strategies for mitigating side effects.

\section{Decreasing side effects}

Nausea is the most common side effect associated with varenicline. ${ }^{27,28}$ If patients experience nausea which prompts them to consider therapy discontinuation, we advocate educating them on the importance of taking varenicline with food and an $8 \mathrm{oz}$ glass of water. If these interventions do not improve symptoms, the daily dose of varenicline can be reduced because nausea appears to be a dose-dependent adverse effect. ${ }^{54}$ Varenicline remains more efficacious than placebo when the daily dose is halved (to $0.5 \mathrm{mg}$ twice daily) and taken for 12 weeks. Week 9-52 abstinence rates were $18.5 \%$ for subjects who received $0.5 \mathrm{mg}$ varenicline twice daily compared with $3.9 \%$ for subjects who received placebo $(P<0.001){ }^{55}$

The half-life of varenicline is approximately 17 hours supporting once-a-day dosing. ${ }^{56}$ However, splitting the dose into two doses per day is believed to reduce the incidence of nausea and vomiting. ${ }^{54}$ Dividing the daily dose further into more than two administrations per day may be an effective strategy for mitigating these symptoms in patients already taking the drug twice daily.

\section{Increasing efficacy in patients who have difficulty remaining abstinent}

The treatment of tobacco dependence is characterized by relapses and remissions, and patients often make many quit attempts before achieving long-term smoking abstinence. ${ }^{13}$ As previously discussed, smokers who are unable to quit smoking on their target quit date, but who eventually quit during the treatment period with varenicline appear to benefit from an additional 12 weeks of therapy. ${ }^{32}$ We recommend maintenance therapy as an effective strategy for relapse prevention in smokers who are initially unsuccessful at quitting.

Preliminary evidence suggests that partial responders to varenicline may benefit from an increased dose. A small case-control study $(n=56)$ observed that increasing the dose of varenicline from $2 \mathrm{mg}$ per day to $3 \mathrm{mg}$ per day at week 6 in highly nicotine-dependent partial responders to varenicline (ie, smokers who reduce cigarette consumption but fail to quit at week 6 while on drug) may be effective. Compared with control cases who failed to achieve early abstinence while on 12 weeks of varenicline at $2 \mathrm{mg}$ per day, dose-escalated patients had more favorable smoking abstinence outcomes (seven-day point prevalence) at week 12 (35.7\% versus $14.3 \%$, OR 3.33, 95\% CI: 0.90-12.36). ${ }^{57}$ Although this dosing regimen is not approved by the FDA, and these findings have yet to be validated in a larger controlled clinical trial, highlydependent smokers may benefit from this approach.

\section{Patient selection}

Varenicline is an FDA pregnancy category $\mathrm{C}$ drug. Studies on rats and rabbits observed decreased fetal weight and decreased offspring fertility after administration of high doses of varenicline. The effects of varenicline on pregnant humans and their offspring have not been adequately investigated, nor is it known whether varenicline is excreted in the 
milk of nursing mothers. ${ }^{58}$ For this reason, varenicline is not recommended for pregnant or nursing mothers unless the drug's benefit justifies the potential risk posed to the fetus. Care should be taken in patients with severe renal dysfunction (creatinine clearance $<30 \mathrm{~mL} / \mathrm{min}$ ); decreasing the dose to $0.5 \mathrm{mg} /$ day is recommended for this patient population. ${ }^{13}$

\section{Conclusion}

Not every quit attempt made by a smoker will be successful, but combined behavioral therapy and pharmacotherapy significantly improves the odds of achieving tobacco abstinence. Smokers taking varenicline have the most success quitting compared with those taking other first-line pharmacotherapies for treating tobacco dependence. Although barriers, such as unsuccessful quit attempts and adverse side effects, may decrease adherence and impair patient satisfaction with tobacco dependence treatment, clinicians should work with patients to adjust pharmacotherapy to suit the individual patient's needs and help the smoker achieve long-term smoking abstinence.

\section{Disclosure}

The authors report no conflict of interests in this work.

\section{References}

1. Cigarette smoking among adults and trends in smoking cessation - United States, 2008. MMWR Morb Mortal Wkly Rep. 2009;58(44):1227-1232.

2. Annual smoking-attributable mortality, years of potential life lost, and economic costs - United States, 1995-1999. MMWR Morb Mortal Wkly Rep. 2002;51(14):300-303.

3. Mackay J, Eriksen M. The Tobacco Atlas. Geneva, Switzerland: World Health Organization; 2002.

4. Centers for Disease Control and Prevention. The health consequences of smoking: A report of the Surgeon General. Available at: http:// www.cdc.gov/tobacco/data_statistics/sgr/2004/index.htm. Accessed Aug 19, 2010.

5. Mokdad AH, Marks JS, Stroup DF, Gerberding JL. Actual causes of death in the United States, 2000. JAMA. 2004;291(10):1238-1245.

6. Smoking-attributable mortality, years of potential life lost, and productivity losses - United States, 2000-2004. MMWR Morb Mortal Wkly Rep. 2008;57(45):1226-1228.

7. US Department of Health and Human Services. The Health Benefits of Smoking Cessation: A report of the Surgeon General. Atlanta, GA: US Department of Health and Human Services; 1990.

8. Mulcahy R. Influence of cigarette smoking on morbidity and mortality after myocardial infarction. Br Heart J. 1983;49(5):410-415.

9. Godtfredsen NS, Lam TH, Hansel TT, et al. COPD-related morbidity and mortality after smoking cessation: Status of the evidence. Eur Respir J. 2008;32(4):844-853.

10. Cigarette smoking among adults - United States, 2000. MMWR Morb Mortal Wkly Rep. 2002;51(29):642-645.

11. Zhu S-H, Melcer T, Sun J, Rosbrook B, Pierce JP. Smoking cessation with and without assistance: A population-based analysis. Am J Prev Med. 2000;18(4):305-311.

12. Hughes JR, Keely J, Naud S. Shape of the relapse curve and long-term abstinence among untreated smokers. Addiction. 2004;99(1): 29-38.
13. Fiore MC, Bailey WC, Cohen S, et al. Clinical Practice Guideline: Treating tobacco use and dependence. Rockville, MD: US Department of Health and Human Services, Public Health Service; 2008.

14. Hurt RD, Ebbert JO, Hays JT, McFadden DD. Treating tobacco dependence in a medical setting. CA Cancer J Clin. 2009;59(5):314-326.

15. US Department of Health and Human Services. The Health Consequences of Smoking: Nicotine addiction. A report of the Surgeon General. Washington, DC: US Government Printing Office; 1988.

16. Rollema H, Coe JW, Chambers LK, Hurst RS, Stahl SM, Williams KE. Rationale, pharmacology and clinical efficacy of partial agonists of $\alpha_{4} \beta_{2}$ nACh receptors for smoking cessation. Trends Pharmacol Sci. 2007;28(7):316-325.

17. Dani JA. Roles of dopamine signaling in nicotine addiction. $\mathrm{Mol}$ Psychiatry. 2003;8(3):255-256.

18. Changeux J-P. Nicotine addiction and nicotinic receptors: Lessons from genetically modified mice. Nat Rev Neurosci. 2010; 11(6):389-401.

19. Jensen AA, Frølund B, Liljefors T, Krogsgaard-Larsen P. Neuronal nicotinic acetylcholine receptors: Structural revelations, target identifications, and therapeutic inspirations. J Med Chem. 2005;48(15):4705-4745.

20. Wonnacott S, Sidhpura N, Balfour DJ. Nicotine: From molecular mechanisms to behaviour. Curr Opin Pharmacol. 2005;5(1):53-59.

21. Papke RL, Heinemann SF. Partial agonist properties of cytisine on neuronal nicotinic receptors containing the beta 2 subunit. Mol Pharmacol. 1994;45(1):142-149.

22. Etter J-F. Cytisine for smoking cessation: A literature review and a meta-analysis. Arch Intern Med. 2006;166(15):1553-1559.

23. Barlow RB, McLeod LJ. Some studies on cytisine and its methylated derivatives. Br J Pharmacol. 1969;35(1):161-174.

24. Reavill C, Walther B, Stolerman IP, Testa B. Behavioural and pharmacokinetic studies on nicotine, cytisine and lobeline. Neuropharmacology. 1990;29(7):619-624.

25. Coe JW, Brooks PR, Vetelino MG, et al. Varenicline: An $\alpha_{4} \beta_{2}$ nicotinic receptor partial agonist for smoking cessation. J Med Chem. 2005;48(10):3474-3477.

26. Mihalak KB, Carroll FI, Luetje CW. Varenicline is a partial agonist at alpha4beta2 and a full agonist at alpha7 neuronal nicotinic receptors. Mol Pharmacol. 2006;70(3):801-805.

27. Gonzales D, Rennard SI, Nides M, et al. Varenicline, an $\alpha_{4} \beta_{2}$ nicotinic acetylcholine receptor partial agonist, versus sustained-release bupropion and placebo for smoking cessation: A randomized controlled trial. JAMA. 2006;296(1):47-55.

28. Jorenby DE, Hays JT, Rigotti NA, et al. Efficacy of varenicline, an $\alpha_{4} \beta_{2}$ nicotinic acetylcholine receptor partial agonist, versus placebo or sustained-release bupropion for smoking cessation: A randomized controlled trial. JAMA. 2006;296(1):56-63.

29. Aubin HJ, Bobak A, Britton JR, et al. Varenicline versus transdermal nicotine patch for smoking cessation: Results from a randomised openlabel trial. Thorax. 2008;63(8):717-724.

30. Cahill K, Stead LF, Lancaster T. Nicotine receptor partial agonists for smoking cessation. Cochrane Database Syst Rev. 2009;1.

31. Tonstad S, Tonnesen P, Hajek P, et al. Effect of maintenance therapy with varenicline on smoking cessation: A randomized controlled trial. JAMA. 2006;296(1):64-71.

32. Hajek P, Tonnesen P, Arteaga C, Russ C, Tonstad S. Varenicline in prevention of relapse to smoking: Effect of quit pattern on response to extended treatment. Addiction. 2009;104(9):1597-1602.

33. Williams KE, Reeves KR, Billing CB Jr, Pennington AM, Gong J. A double-blind study evaluating the long-term safety of varenicline for smoking cessation. Curr Med Res Opin. 2007;23(4):793-801.

34. Ebbert JO, Hays JT, Hurt RD. Combination pharmacotherapy for stopping smoking: What advantages does it offer? Drugs. 2010;70(6):643-650.

35. Ebbert JO, Croghan IT, Sood A, Schroeder DR, Hays JT, Hurt RD. Varenicline and bupropion sustained-release combination therapy for smoking cessation. Nicotine Tob Res. 2009;11(3):234-239. 
36. Ebbert JO, Burke MV, Hays JT, Hurt RD. Combination treatment with varenicline and nicotine replacement therapy. Nicotine Tob Res. 2009;11(5):572-576.

37. Solberg LI, Parker ED, Foldes SS, Walker PF. Disparities in tobacco cessation medication orders and fills among special populations. Nicotine Tob Res. 2010;12(2):144-151.

38. Hays JT, Leischow SJ, Lawrence D, Lee TC. Adherence to treatment for tobacco dependence: Association with smoking abstinence and predictors of adherence. Nicotine Tob Res. 2010;12(6):574-581.

39. Schauffler HH, McMenamin S, Olson K, Boyce-Smith G, Rideout JA, Kamil J. Variations in treatment benefits influence smoking cessation: Results of a randomised controlled trial. Tob Control. 2001;10(2):175-180.

40. Curry SJ, Grothaus LC, McAfee T, Pabiniak C. Use and cost effectiveness of smoking-cessation services under four insurance plans in a health maintenance organization. $N$ Engl J Med. 1998;339(10): 673-679.

41. Petersen R, Garrett JM, Melvin CL, Hartmann KE. Medicaid reimbursement for prenatal smoking intervention influences quitting and cessation. Tob Control. 2006;15(1):30-34.

42. Howard P, Knight C, Boler A, Baker C. Cost-utility analysis of varenicline versus existing smoking cessation strategies using the BENESCO simulation model: Application to a population of US adult smokers. Pharmacoeconomics. 2008;26(6):497-511.

43. Linden K, Jormanainen V, Linna M, Sintonen H, Wilson K, Kotomaki T. Cost effectiveness of varenicline versus bupropion and unaided cessation for smoking cessation in a cohort of Finnish adult smokers. Curr Med Res Opin. 2010;26(3):549-560.

44. Annemans L, Nackaerts K, Bartsch P, Prignot J, Marbaix S. Cost effectiveness of varenicline in Belgium, compared with bupropion, nicotine replacement therapy, brief counselling and unaided smoking cessation: A BENESCO Markov cost-effectiveness analysis. Clin Drug Investig. 2009;29(10):655-665.

45. Bolin K, Mork AC, Willers S, Lindgren B. Varenicline as compared with bupropion in smoking-cessation therapy - cost-utility results for Sweden 2003. Respir Med. 2008;102(5):699-710.

46. Hoogendoorn M, Welsing P, Rutten-van Molken MP. Cost-effectiveness of varenicline compared with bupropion, NRT, and nortriptyline for smoking cessation in the Netherlands. Curr Med Res Opin. 2008; 24(1):51-61.

47. Knight C, Howard P, Baker CL, Marton JP. The cost-effectiveness of an extended course $(12+12$ weeks $)$ of varenicline compared with other available smoking cessation strategies in the United States: An extension and update to the BENESCO model. Value Health. 2009;13(2):209-214.
48. US Food and Drug Administration. Early communication about an ongoing safety review of varenicline (marketed as Chantix). Nov 20, 2010. Available at: http://www.fda.gov/Drugs/DrugSafety/PostmarketDrug SafetyInformationforPatientsandProviders/DrugSafetyInformationfor HeathcareProfessionals/ucm070765.htm. Accessed May 25, 2010.

49. US Food and Drug Administration. Varenicline (marketed as Chantix) Information. May 16, 2008. Available at: http:/www.fda.gov/Drugs/ DrugSafety/PostmarketDrugSafetyInformationforPatientsandProvid ers/ucm106540.htm. Accessed May 25, 2010.

50. US Food and Drug Administration. Public Health Advisory: FDA requires new boxed warnings for the smoking cessation drugs Chantix and Zyban. Jul 1, 2009. Available at: http://www.fda.gov/Drugs/DrugSafety/Pub licHealthAdvisories/ucm169988.htm. Accessed May 25, 2010

51. American Psychiatric Association. Diagnostic and Statistical Manual of Mental Disorders. 4th edition, text revision. Washington, DC: American Psychiatric Association; 2000.

52. Tonstad S, Davies S, Flammer M, Russ C, Hughes J. Psychiatric adverse events in randomized, double-blind, placebo-controlled clinical trials of varenicline: a pooled analysis. Drug Saf. 2010;33(4):289-301.

53. US Food and Drug Administration. FDA: Boxed warning on serious mental health events to be required for Chantix and Zyban. Available at: http://www.fda.gov/NewsEvents/Newsroom/PressAnnouncements/ ucm170100.htm. Accessed May 26, 2010.

54. Faessel HM, Gibbs MA, Clark DJ, Rohrbacher K, Stolar M, Burstein AH. Multiple-dose pharmacokinetics of the selective nicotinic receptor partial agonist, varenicline, in healthy smokers. J Clin Pharmacol. 2006;46(12):1439-1448.

55. Oncken C, Gonzales D, Nides M, et al. Efficacy and safety of the novel selective nicotinic acetylcholine receptor partial agonist, varenicline, for smoking cessation. Arch Intern Med. 2006;166(15):1571-1577.

56. Obach RS, Reed-Hagen AE, Krueger SS, et al. Metabolism and disposition of varenicline, a selective $\alpha_{4} \beta_{2}$ acetylcholine receptor partial agonist, in vivo and in vitro. Drug Metab Dispos. 2006;34(1):121-130.

57. Karam-Hage M, Lam C, Blalock J, Cinciripini P. Increasing varenicline to $3 \mathrm{mgs} /$ day improves abstinence rates: A preliminary efficacy report in cancer patients. Paper presented at: Society for Research on Nicotine and Tobacco Annual Meeting, Feb 25, 2010, Baltimore, MD.

58. Chantix ${ }^{\mathbb{B}}$ (varenicline) prescribing information. Available at: http://media. pfizer.com/files/products/uspi_chantix.pdf. Accessed Jun 3, 2010.
Patient Preference and Adherence

\section{Publish your work in this journal}

Patient Preference and Adherence is an international, peer-reviewed, open access journal focusing on the growing importance of patient preference and adherence throughout the therapeutic continuum. Patient satisfaction, acceptability, quality of life, compliance, persistence and their role in developing new therapeutic modalities and compounds to

\section{Dovepress}

optimize clinical outcomes for existing disease states are major areas of interest. This journal has been accepted for indexing on PubMed Central. The manuscript management system is completely online and includes a very quick and fair peer-review system. Visit http://www.dovepress.com/ testimonials.php to read real quotes from published authors. 